coming into being. Very occasionally something seems to have gone wrong: for example, Fig. 1 does not correspond well with Fig. 28 or with Fig. 3, which is inadequately explained; and Fig. 51 does not show energy peaks at the frequencies where the legend says they should be; the epithet 'Kaspar Hauser', which is used repeatedly, is explained only in one footnote, which is not indexed. But these are small faults. The book is a worthy member of a distinguished series. If there is anyone who numbers among his friends an ornithologist to whom he has forgotten to send a present, here is his opportunity to make amends.

\section{R. J. PUMphrey}

\section{ART AND FORM IN GLASS}

Glass in Architecture and Decoration

By Raymond McGrath and A. C. Frost. New edition revised by Raymond McGrath. With a section on the Nature and Properties of Glass by H. E. Beckett. Pp. 712 (418 photographs). (London: The Architectural Press, 1961.) 126s. net.

$\mathrm{N}$ the preface to this second edition of a book first 1 published twenty-four years ago is the following interesting observation: "Architects and writers about architecture often refer to the increasing 'tyranny of materials' but it is hard to see that the technical development of manufacturers, which is nothing new but only seems so from its present acceleration, can be anything but a liberation from older tyrannies which we have grown used to", a quotation which is eloquently developed in the pages of this luxurious book. The new edition has been brought up to date, the historical section on glass manufacture now concludes with a brief reference to the float process first announced a year or so ago and the beautiful collection of photographs illustrating the use of glass in buildings has been changed considerably. Many of the photographs are of things which did not exist when the first edition was published, including, for example, the Lever, Seagram and the United Nations Buildings in New York, some notable school buildings in the United Kingdom and some interesting modern interpretations of 'stained glass'.

The title is very modest, for the book is divided into five sections; the making of glass, glass in architecture, glass in decoration, the nature and properties of glass, the working, glazing and fixing of glass; there is also an appendix on British building glasses which will, no doubt, be very useful to those to whom the book is primarily addressed. The section on the making of glass contains an excellent survey of the history of glassmaking from the earliest times until about 1850: from then on the treatment is more detailed and more specifically concerned with flat glass. At the end of the volume there is a bibliography which contains a good list of books on the history of the subject. The photographs of manufacturing processes are first class.

The section on the nature and properties of glass is adequate in a hundred of the very large pages, although having started with a brief mention of early work on the X-ray diffraction by glasses, it skates lightly over the thermodynamical problems of glass formation to deal with the daylight factors of windows, coloured glasses and, eventually, descrip- tions of the manufacture and use of pavement lights, fibre glass, radiation, absorbing windows and photosensitive glass: even this list is not exhaustive.

Modern 'stained' glass is given very sympathetic treatment and is happily illustrated with examples of the work of Henri Matisse, Fernand Leger, John Piper and others. Unfortunately glass cutting and engraving of table glass receive very little consideration: one would have liked the author to stray a little more from his general thesis here. However, the book undoubtedly is written primarily for the architect and it contains much useful factual information on flat glass. It is not surprising that the section on glass in architecture should be the longest. The first thirty pages of this section form a persuasive essay in support of the role of the development of glass as a liberating agent in architecture.

Almost any reader could get some pleasure from a perusal of this volume, which must also be a very valuable reference work for the professional user.

R. W. Douglas

\section{ATMOSPHERIC DIFFUSION}

\section{Atmospheric Diffusion}

The Dispersion of Windborne Material from Industrial and other Sources. By Dr. F. Pasquill. Pp. xii +297. (London: D. Van Nostrand Company, Ltd.; Princeton, N.J.: D. Van Nostrand Company, Inc., 1961.) $60 s$.

$\mathrm{M}$

ANY notable scientists have matched themselves against the problems of turbulence-Reynolds, Prandtl, Richardson, Taylor, von Kármán and Kolmogoroff are among them-but the subject remains distinctly intractable, and no comprehensive theory has yet emerged, even for homogeneous fluids much less for density-stratified fluids such as our atmosphere. Nevertheless, theory has suggested appropriate descriptions of turbulence, for example, spatial and temporal velocity correlation functions and the corresponding spectra, the techniques have come to hand to effect such descriptions (though Lagrangian correlation remains a problem), and there is a developing interaction between observation and theory as a result. Thus, although answers to many important and practical problems in turbulent diffusion, not least in the atmosphere, must depend heavily on observations in the different elasses of diffusion problem, the empiricism of the subject has become rather well framed by theory and a systematic exposition of the present body of knowledge is indeed timely. Dr. Pasquill, who has been in the van of experimental investigations of atmospheric diffusion over some years and who has lately added notably to its theory, has performed a great service to the subject in providing the exposition here under review.

Pasquill's treatment is first, in three chapters, to describe the technique for a statistical analysis of turbulence, so far at least as its propertios are of immediate concern to the diffusion of inert substance; to provide a broad review of these statistics as observed in the atmosphere up to a height of about $1 \mathrm{~km}$.; and then to develop the theoretical treatments of atmospheric diffusion, from the early and quite formal Fickian eddy diffusivity or ' $K$ ' theory to the recent transfer-theory of Russian workers and the statistical theory deriving from Taylor, Richardson and Batchelor and developed by Pasquill and his 